\title{
Spine surgery in pregnant women: a multicenter case series and proposition of treatment algorithm
}

\author{
Vicki M. Butenschoen ${ }^{1}$ (1) - Hanna Hitscherich ${ }^{1} \cdot$ Sven O. Eicker $^{2} \cdot$ Silvia M. Lobmaier ${ }^{6} \cdot$ Judith Rösler $^{3}$. \\ Martin Bretschneider ${ }^{7}$. Jan S. Kirschke ${ }^{8} \cdot$ Peter Vajkoczy $^{3} \cdot$ Nikolaus Kögl $^{4} \cdot$ Paul Constanthin $^{5} \cdot$ Claudius Thome $^{4}$. \\ Enrico Tessitore ${ }^{5} \cdot$ Bernhard Meyer $^{1} \cdot$ Maria Wostrack $^{1}$
}

Received: 4 November 2020 / Revised: 4 November 2020 / Accepted: 6 January 2021 / Published online: 25 January 2021

(c) The Author(s) 2021

\begin{abstract}
Purpose Spinal diseases requiring urgent surgical treatment are rare during pregnancy. Evidence is sparse and data are only available in the form of case reports. Our aim is to provide a comprehensive guide for spinal surgery on pregnant patients and highlight diagnostic and therapeutic aspects.

Methods The study included a cohort of consecutive pregnant patients who underwent spinal surgery at five high-volume neurosurgical centers between 2010 and 2017. Perioperative and perinatal clinical data were derived from medical records. Results Twenty-four pregnant patients were included. Three underwent a preoperative cesarean section. Twenty-one patients underwent surgery during pregnancy. Median maternal age was 33 years, and median gestational age was 13 completed weeks. Indications were: lumbar disk prolapse ( $n=14$; including cauda equina, severe motor deficits or acute pain), unstable spine injuries $(n=4)$; intramedullary tumor with paraparesis $(n=1)$, infection $(n=1)$ and Schwann cell nerve root tumor presenting with high-grade paresis $(n=1)$. Two patients suffered transient gestational diabetes and 1 patient presented with vaginal bleeding without any signs of fetal complications. No miscarriages, stillbirths, or severe obstetric complications occurred until delivery. All patients improved neurologically after the surgery.

Conclusion Spinal surgical procedures during pregnancy seem to be safe. The indication for surgery has to be very strict and surgical procedures during pregnancy should be reserved for emergency cases. For pregnant patients, the surgical strategy should be individually tailored to the mother and the fetus.
\end{abstract}

Keywords Pregnancy $\cdot$ Spine surgery

\section{Introduction}

Back pain is a common symptom of pregnancy and occurs in up to $56 \%$ of pregnant women [1]. Previous studies correlated lower lumbar spine pain and pelvic pain with increased levels of relaxin, a hormone produced primarily by the corpus luteum during pregnancy [2]. However, biomechanical changes, weight gain and sagittal imbalance are also possible etiologies.

Surgery-requiring nerve root compression syndromes caused by herniated disks during pregnancy are less common and affect approximately 1 in 10,000 pregnant women [3]. Other spinal diseases, such as tumors, bony injuries

Vicki M. Butenschoen

Vicki.Butenschoen@tum.de

Extended author information available on the last page of the article and infections, are much more rarely encountered during pregnancy. Several diagnostic and therapeutic aspects are to consider, especially when a surgical approach during pregnancy is required: which drugs and diagnostic tests are safe to use, the indication for surgery, the optimum timing and technique for the procedure, appropriate anesthesia, perioperative pregnancy monitoring and when to follow-up.

Only sparse evidence exists in the literature on these issues and they are mainly available in the form of case reports and small case series $[4,5]$. So far, no standard protocol for such clinical situations has been established. In contrast, the topic is becoming more relevant as the prevalence of acute spinal symptoms during pregnancy increases due to the increasing age of pregnant women. 


\section{Methods}

\section{Patient population}

A multicenter study including consecutive pregnant patients who underwent spinal surgery at five high-volume neurosurgical centers between 2010 and 2017 was performed (Germany: 3, Austria: 1, Switzerland: 1). Preoperative, operative and postoperative clinical data were retrieved retrospectively from medical records. Patients were scheduled for the followup examination to evaluate the peri- and postpartum outcome using a standardized questionnaire including data on the course of pregnancy and the neurological outcome.

The following parameters were captured for further evaluation: maternal age and gestational age at the time of the surgery, neurological symptoms before surgery and at discharge, perioperative surgery-related complications, pregnancy history based on gynecological monitoring (clinical findings, cardiotocography [CTG] curves), gynecological complications in the perioperative period, operative diagnosis, preoperative, intraoperative and postoperative imaging. Surgical data included: positioning of the patient, surgical approach, duration of the surgery, intraoperative complications and special features of the anesthetic approach (type of anesthesia, duration, complications, peri- and postoperative monitoring).

In a separate follow-up examination, the following criteria were recorded: pregnancy outcome, perinatal parameters, as documented in the maternity record [6] and clinical symptoms according to the routine neurological examination (examination of sensorimotor function, survey of the current pain situation via VAS, reflexes, vegetative symptoms, etc.).

The results were compared with the preoperative data and dichotomized into "worsened," "improved, incomplete convalescence," "improved, complete convalescence," and "unchanged."

\section{Statistical analysis}

Statistical analysis was performed with the Excel Statistics package Version 16.19 (@Microsoft 2018) and SPSS (IBM, Version 26). We used Fisher's exact test for binomial dichotomized data and the chi-square test for categorical data. Median or mean values were compared using a Student's t test. The association between potential factors and perinatal complications were analyzed using ANOVA for variance testing and linear regression modeling. $P$ values less than 0.05 were considered statistically significant.

\section{Ethics}

The study was performed in accordance with the Declaration of Helsinki. Approval for the study was obtained from the ethics committees of the Technical University of Munich (Votum Number 83/17 S) and University of Innsbruck (Votum Number 1239/2017).

\section{Results}

\section{Patient population}

Overall, 24 pregnant patients were assigned to spinal surgery, all of them with urgent indications. Three of them underwent a preoperative cesarean section in the 33rd and one in the 31st week of gestation and were excluded from further analysis.

The remaining 21 patients underwent surgery during pregnancy. Three patients were operated upon twice or more during the same pregnancy ( 1 patient had incomplete tumor resection after the first treatment for ependymoma, 1 patient had to undergo abscess surgery twice and 1 patient completed a dorsoventral approach). The median maternal age was 33 years (range 22-41 years), median gestational age was 13 completed weeks (range 7-34 weeks). The indications were lumbar herniated intervertebral disks $(n=14)$ presenting with cauda equina syndrome in 4 cases, highgrade motor deficit in 7 cases and acute pain in 3 cases; traumatic spine injuries $(n=4)$; intramedullary tumor with paraparesis (ependymoma, $n=1$ ); paraspinal infection $(n=1)$; and Schwann cell nerve root tumor presenting with higher-graded paresis $(n=1$; Table 1$)$.

\section{Perioperative and surgical management}

Perioperative pregnancy monitoring was performed with an ultrasound or ultrasound plus CTG after the 24th week of gestation in the majority of cases. All surgeries were performed under general anesthesia (balanced anesthesia $n=12$,

Table 1 Demographics and indication for surgical treatment. Most patients presented with lumbar disk herniation causing severe motor deficits (33.3\%), cauda equina (19\%) or traumatic spine injury (19\%)

\begin{tabular}{ll}
\hline Median maternal age (range) & 33 years $(22-41)$ \\
Median Gestational Age (range) & 13 weeks (7-34) \\
Indication \% $(n)$ & \\
Lumbar Disk Herniation & $66.7(14)$ \\
Cauda equina & $19(4)$ \\
Motor deficit & $33.3(7)$ \\
Acute pain & $14.3(3)$ \\
Trauma & $19(4)$ \\
Tumor & $9.5(2)$ \\
Schwannoma & $4.8(1)$ \\
Ependymoma & $4.8(1)$ \\
Infection & $4.8(1)$ \\
\hline
\end{tabular}


$57.1 \%$, total intravenous anesthesia $n=9,42.9 \%$ ). Median duration of surgery was $90 \mathrm{~min}$ (range 41-240 min). Fifteen patients were placed in a prone position (71.4\%) and 6 in a right or left lateral decubitus position depending on the gestational age and the type of surgery (28.6\%). Perioperative aspects are listed in Table 2.

Preoperative imaging diagnostics included MRI in 19 $(90.5 \%)$ cases, CT in 2 cases $(9.5 \%)$ and $\mathrm{x}$-ray in 3 cases (14.3\%). In 9 cases, no intraoperative fluoroscopy was applied (42.9\%). In 12 cases (57.1\%), fluoroscopic verification of spine level or guidance of instrumentation placement was performed with a median fluoroscopic time of $6 \mathrm{~s}$ (range 1-24 s). Among surgery-related complications, only one deep wound infection was observed. Performance of fluoroscopy did not increase the risk of peripartal complications.

Two patients decided on medical abortion due to radiation exposure before the early pregnancy was diagnosed $(9.5 \%)$. Among the other 19 patients, 2 suffered transient gestational diabetes $(9.5 \%)$ and 1 patient presented with vaginal bleeding without any signs of fetal complications during the early postoperative in-hospital stay.

\section{Follow-up and peripartal complications}

Neurosurgical follow-up data were available for 18 of 21 patients $(85.7 \%)$, with a median follow-up duration of 330 days ( 11 months, range 40 days to 6 years). According to these data, no miscarriages, stillbirths, or other severe obstetric complications occurred during the further course of pregnancy. All patients improved neurologically after the surgery (partially vs. fully), either at discharge or during the latter follow-up.

The median gestational age at delivery was $38+0$ weeks (range $34+0$ to $41+5$ weeks). The median birth weight was $3030 \mathrm{~g}$ (range $2370-4180 \mathrm{~g}$ ). No neonates were found to be too small for gestational age. The percentile ranged between 31st and 96th for birth weight, between 36 and 88th for length and between 41st and 90th for head circumference. Peripartal complications were observed in 2 patients (9.5\%): 1 patient suffered from a urinary tract infection and 1 patient from a retrochorial hematoma with premature placental separation. We did not observe any cases of perinatal

Table 2 Surgical parameters and anesthesia (TIVA: total intravenous anesthesia), most patients were placed in a prone position $(71.4 \%)$

\begin{tabular}{ll}
\hline Anesthesia $\%(n)$ & \\
Balanced & $57.1(12)$ \\
TIVA & $42.9(9)$ \\
Median duration of surgery (range) & $90 \mathrm{~min}(41-240)$ \\
Position & \\
Prone & $71.4(15)$ \\
Decubitus position & $28.6(6)$ \\
\hline
\end{tabular}

mortality or any congenital malformations after fluoroscopic exposure, nor any significant influencing factors increasing the risk for peripartal complications.

\section{Selected cases}

\section{Case 1}

A 34 year-old women presented with acute cauda equina syndrome (loss of bladder and sphincter control, pain radiating to the $\mathrm{S} 1$ dermatome, genital hypoesthesia). The patient was pregnant (10 weeks of gestation). The MRI without contrast enhancing revealed a disk prolapse at the L5/S1 level (Fig. 1). The patient was scheduled for emergency surgery on the same day. The surgical treatment included a sequestrectomy via L5/S1 fenestration on the left side in prone position, duration of surgery was $88 \mathrm{~min}$ and anesthesia was balanced. No perioperative complications occurred and the patient gave birth to a healthy girl at 41 weeks (birth weight $4180 \mathrm{~g}$ ). At 6 years' follow-up, she remained free of symptoms and without neurological deficits.

Case 2

A 34 year-old pregnant patient (gestational age 19 weeks) presented in the outpatient emergency department with progressive genital hypoesthesia and incomplete paraplegia of the lower extremities. An MRI revealed an intramedullary tumor at Th10/11 (Fig. 2), which was biopsied through a hemilaminectomy at Th10-Th11 (surgery duration $198 \mathrm{~min}$, TIVA anesthesia) in prone position. Histopathology detected a WHO grade II ependymoma; therefore, the indication for a tumor resection was taken. The patient underwent an uneventful gross total resection 1 week later (surgery duration $165 \mathrm{~min}$, TIVA anesthesia, intraoperative neuromonitoring with motor evoked potentials). No perioperative complications occurred and the patient gave birth at 33 weeks (birth weight $2990 \mathrm{~g}$ ). The incomplete paraplegia improved at follow-up after 5 years to a minor paresis of the left leg.

Case 3

A 39-year old patient presented at 33 weeks of gestation in the outpatient department with paresis of her left foot extension graded MRC 3/5 for $24 \mathrm{~h}$ and pain radiating to the left L5 dermatome due to a disk prolapse at L4/5 on the left side (Fig. 3). In two different hospitals, she was recommended for a surgical intervention after delivery. Due to the paresis of the left foot, the patient was advised to undergo urgent surgical therapy during pregnancy. She underwent a fenestration at L4/L5 on the left side with sequestrectomy (surgery duration $58 \mathrm{~min}$, left lateral decubitus position, balanced anesthesia, intraoperative x-ray scan for verification of spine level). Postoperative CTG control was normal. Three weeks later, she delivered a healthy baby (birth weight $3030 \mathrm{~g}$ ) without complications. After 14 months' follow-up, no residual neurological deficits were present. 
Fig. 1 MR imaging of the lumbar spine with sagittal (left) and axial (right) sequencing showing a disk prolapse at the level L5/S1 on the left side

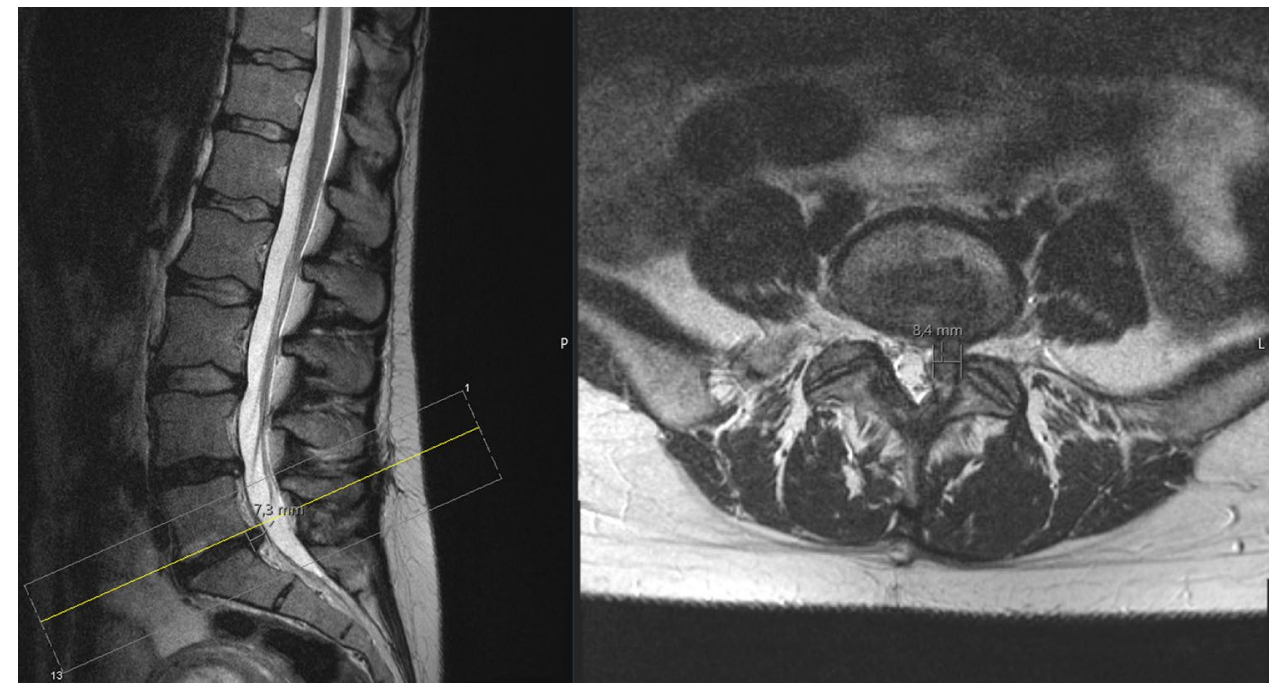

Fig. 2 MR imaging of the thoracic spine with sagittal (left) and axial (right) sequencing and contrast enhancement revealing an intramedullary tumor at the level Th10/Th11

Fig. 3 MR imaging of the lumbar spine with sagittal (left) and axial (right) sequencing showing a disk prolapse at the level L4/L5 in a pregnant woman with left foot extension paresis
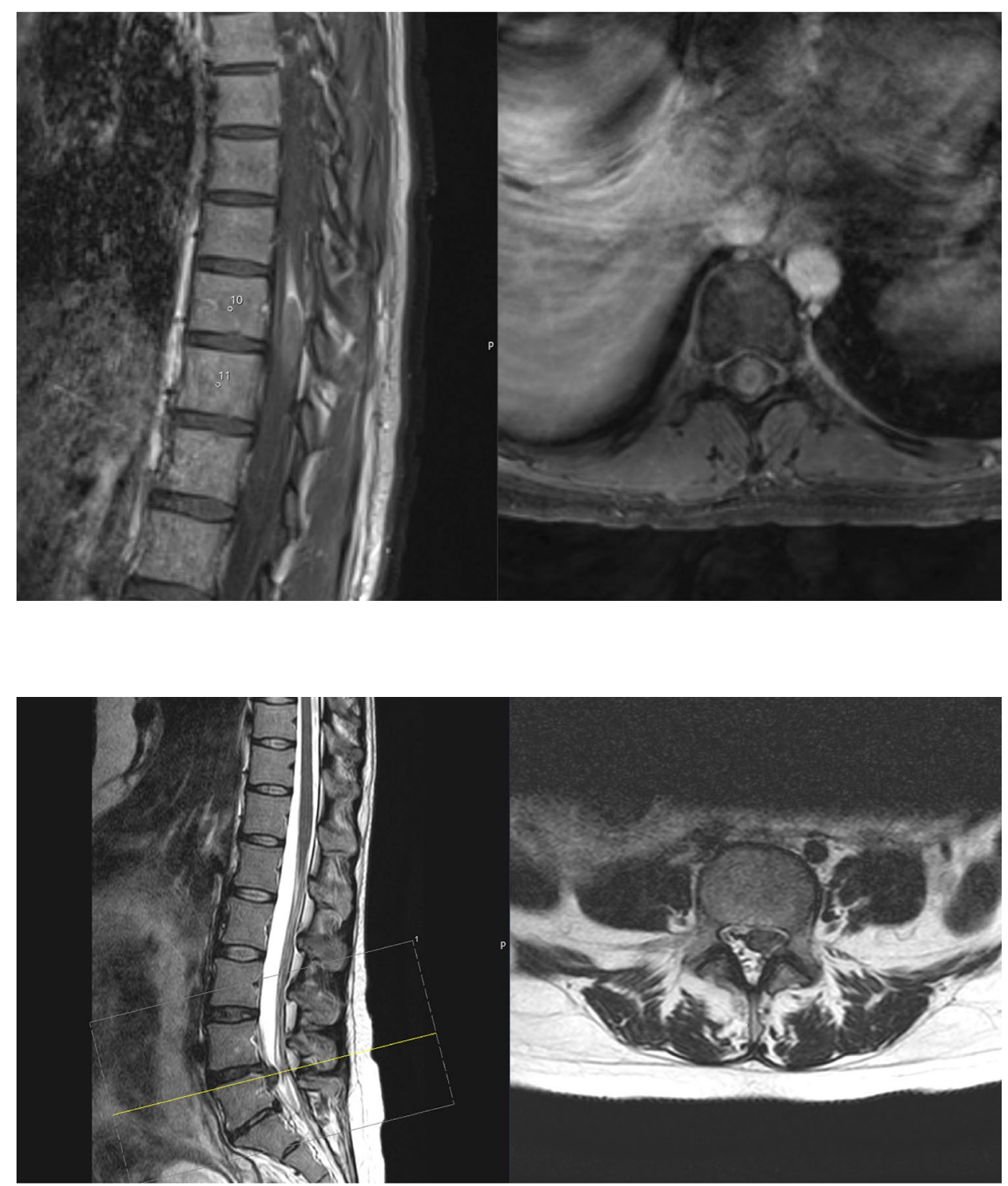


\section{Discussion and recommendations}

\section{Surgical indication and perioperative risk assessment}

The incidence of non-obstetric surgical interventions in pregnant women is 1-2\% [7]. According to the recommendation of the American Society of Obstetricians and Gynecologists' Committee (ACOG), a surgical indication should not generally be denied due to an existing pregnancy, regardless of the trimester, although elective and less urgent interventions should be postponed if possible [8]. In case of acute spinal compression symptoms, such as cauda equina or conus syndrome, higher-graded radicular paresis and existing or threatening paraplegia, prolonged waiting until delivery or until the time of a possible cesarean section may lead to the development of persistent neurological deficits with significant disability [2].

In two large series of pregnant women undergoing non-obstetric surgery, the most common diseases were appendicitis and cholecystitis [9, 10]. However, both series do not describe interventions at the spinal level. A larger series of 5405 non-obstetric surgical procedures in pregnant women showed no increase in the incidence of congenital malformations or stillbirths compared to the incidence in women who did not undergo surgery during pregnancy [10]. However, the incidence of very low birth weight infants and the number of infants who were born alive but died within 7 days of birth increased. A specific anesthetic or surgical procedure was not associated with an increased incidence of unfavorable perinatal outcomes. Because the vast majority of interventions in the series were due to the acute abdomen, the results cannot be applied to the overall treatment of the spine. In our series, no peripartum abnormalities were noted during the further course. This is in accordance with only two existing previously published smaller series of three and ten pregnant patients, respectively $[4,5]$. However, due to the small number of cases, these data are purely indicative and do not give any reliable indication of the actual impact of the indicated operations.

\section{Imaging procedures}

\section{General principles}

One of the most important challenges in diagnosing pregnant women is the use of imaging techniques, as the potential harmful effects of most methods on the fetus cannot be ruled out. Delay in diagnosis or inadequate diagnostic work-up can potentially cause more harm to both the fetus and the mother than the potential side effects of imaging techniques. Diagnostic tools should always be considered taking into account their utility, radiation exposure, use of the contrast agent, need for proper diagnosis and treatment of the patient.

Ionizing radiation can cause physical and chemical processes that can lead to cellular death, carcinogenesis, or chromosomal aberrations and genetic mutations [11]. The exposure during the first 2 weeks of pregnancy can usually not be controlled, as the pregnancy at this time can usually not be determined with certainty. During organogenesis, which occurs between 2 and 15 weeks, maternal exposure should be minimized, as the fetus suffers most from teratogen effects during this vulnerable period. In the further course, the potential effect of the radiation exposure and the estimated threshold dose of radiation depend on the gestational age: The threshold of the exposure dose at which an "all (death of the embryo)-or-nothing" effect would occur is 50 to $100 \mathrm{mGy}$ in the first $0-2$ weeks of pregnancy; congenital multisystem abnormalities and growth restriction may result from 200-250 mGy exposure at 3-8 weeks gestation; severe mental retardation, IQ deficit and microcephaly may occur at 60-300 mGy exposure at 8-15 weeks; and secondary mental retardation may be caused by $250-280 \mathrm{mGy}$ exposure at 16-25 weeks gestation [11, 12]. It should also be borne in mind that hardly any examinations with a radiation exposure of more than $100 \mathrm{mGy}$ are used in the radiological routine.

\section{MRI during pregnancy}

MRI is the gold standard in the diagnosis of most spinal disorders, especially when it comes to assessing intraspinal space-occupying pathologies and it has been used to assess peripartum disease for over 20 years [13]. There is no clear evidence of fetal damage in MR examinations with $1.5 \mathrm{~T}$ and 3.0 $\mathrm{T}$ devices, according to numerous clinical and preclinical examinations [14]. MRI can and should be used in pregnant patients regardless of their gestational age (US College of Radiology 2007 white paper on MRI safety) [15]. However, some authors continue to express concern about the safety of MRI during pregnancy, which is mainly related to the heating effects of radiofrequency pulses and the effects of noise exposure on the fetus [16]. Recent studies have shown that a native MRI during the first trimester poses no risk of stillbirth, neonatal death, congenital anomalies and hearing or visual impairment in children.

Absolutely contraindicated is the application of the MR contrast agent gadolinium, as it passes through the placental barrier to fetal kidneys and accumulates in the amniotic fluid for a prolonged period, during which toxic gadolinium ions are released from the chelated molecule [17]. A recently published large study found an association between the 
use of gadolinium and an increased risk of rheumatologic, inflammatory or infiltrating skin diseases in infants; stillbirth; and neonatal deaths [18].

\section{Intraoperative fluoroscopy}

Intraoperative imaging is highly warranted in the majority of spinal surgeries to determine the correct height and to place implants securely in the case of instrument procedures. In the case of surgery on pregnant women, there is uncertainty as to how often and to what extent intraoperative fluoroscopy is possible. Radiation exposure during spinal interventions is highly dependent on the procedure itself as well as the fluoroscopic device. The dose for a fluoroscopic height determination in the lateral or antero-posterior beam path averages 0.9 to $1 \mathrm{mGy}$ [19], which is far below the estimated threshold of potentially teratogen effects. However, if possible, fluoroscopy should still be avoided (e.g., estimation of the lumbar level per palpation or screw placement according to anatomical landmarks), or at least reduced to rare short expositions due to unknown late sequel of perinatal exposure. Optionally, a dosimeter can be placed near the situs to record the correct amount of exposure during the surgery. In cases when extensive fluoroscopy is unavoidable, such as polytrauma patients in our series, the indication for induced abortion should be discussed with the attending obstetricians and the patient.

\section{Surgery, positioning and intraoperative fetal monitoring}

Intraoperative positioning should be selected according to the gestational age and location and extent of the lesion. We recommend the prone position in the first and early second trimester, because there is only minimal aortocaval compression by the gravid uterus [20]. After 12 weeks of gestation, we recommend the left lateral position to avoid aortocaval compression [21]. In restricted viewing conditions, tilting the operating table may be helpful.

Fetal heartbeat monitoring during surgery is not used until the 20th week of gestation and CTG monitoring between the 20th and 23rd week is controversial. From the 24th week of pregnancy, fetal heart monitoring can reliably assess abnormal heart rate patterns that could indicate further fetal pathologies. However, it is unclear whether the CTG should be performed during the entire procedure on the spinal column or whether close monitoring immediately before and after the operation would be sufficient, as was done in our series. The pre- and postoperative ultrasound should be performed in every case. According to the recommendation from the ACOG, the decision as to whether CTG monitoring is used intraoperatively should be made individually and adapted to the gestational age, the type of surgery and the equipment and personal equipment and the possibility to act in cases of pathology [8].

\section{Analgesics and antibiotics management}

Ampicillin and cephalosporin, which are listed in FDA category B, have no known teratogen effects [22]. Acetaminophen and some opiates are suitable medications for pain relief during pregnancy, although recent reports of adverse fetal side effects after prolonged long-term maternal use have been reported [23-26]. Nonsteroidal anti-inflammatory drugs are listed under FDA category $\mathrm{C}$ or D and present a risk of congenital anomalies [27].

\section{Anesthesia}

Understanding physiological changes during the different terms of pregnancy is of paramount importance to provide safe anesthesia. An increase in cardiac output and oxygen consumption, as well as reduced functional reserve capacity, put pregnant women particularly at risk for desaturation and hypoxia during induction of anesthesia. In advanced pregnancy (after 20 gestational weeks), the risk for regurgitation and aspiration is elevated. During pregnancy, maternal alkalosis (with $\mathrm{pH}>7.44$ ) is a normal finding and maternal paCO2 as low as $28 \mathrm{mmHg}$ is physiological to facilitate transfer of maternal oxygen to the fetus.

Nearly all common drugs used in anesthesia can safely be used after the sensible period of organogenesis (15-65 gestational days). Of course, there are no existing drug-safety studies during pregnancy; therefore women usually have to give informed consent for off-label use of anesthetics. Very useful for the safe administration of drugs during pregnancy and lactation period is a web-based platform embryotox.

Both general and regional anesthesia techniques have been successfully used in surgery on pregnant women. Regional anesthesia avoids the potential risk of failure to intubate and aspirate, in addition to reducing the exposure of fetuses to potential teratogens, but previous studies failed to show a clear superiority of a particular technique over the fetal outcome. In anesthesia and surgery, fetal well-being is ensured primarily by careful maintenance of stable maternal hemodynamic parameters and oxygenation.

The consequence of a flat general anesthesia can consequently be a catecholamine increase with the resulting impairment of the uteroplacental perfusion, resulting in an increased risk for the fetus [28]. The maintenance of the mean arterial blood pressure at or above $70 \mathrm{mmHg}$ is strongly recommended [29].

Positive pressure (PEEP) ventilation should be used with caution and the end-tidal carbon dioxide concentration (PaCO2) should be kept within the range normally observed during pregnancy. There is a linear relationship between 
Table 3 Recommendation for treatment algorithm for spine surgery in pregnant women depending on their gestational age, MRI (magnetic resonance imaging) feasible during all stages of pregnancy if necessary and MAP (mean arterial blood pressure) for uteroplacental perfusion

\begin{tabular}{llll}
\hline & $<12$ weeks & 12-24 weeks & $>24$ weeks \\
\hline Diagnostics & MRI & MRI & MRI \\
Positioning & Prone & Left lateral & Left lateral \\
Monitoring & Ultrasound & Ultrasound & CTG \pm Ultrasound \\
MAP Anesthesia & $>70 \mathrm{mmHg}$ & $>70 \mathrm{mmHg}$ & $>70 \mathrm{mmHg}$ \\
Analgetics & Paracetamol, ibuprofen, diclofenac & Paracetamol, ibuprofen, diclofenac & Paracetamol, opioids \\
\hline
\end{tabular}

maternal and fetal PaCO2. Maternal hypercapnia restricts the gradient of $\mathrm{CO} 2$ diffusion from fetal to maternal blood and thus may lead to the development of fetal acidosis with the risk of intrauterine death. We recommend a regular arterial blood gas analysis, especially for longer interventions. Also of concern would be the use of positive end-expiratory pressure ventilation due to the potential impairment of placental perfusion.

One of the main questions concerns the effect of the selected anesthetic and the medication accompanying the anesthetic. Numerous studies have come to the conclusion that virtually every drug used can have teratogen properties at a certain dose and at a certain point of pregnancy [30]. Studies of transplacental drug delivery in humans are difficult for ethical reasons and the applicability of animal studies as models is limited because the anatomy and function of the placenta are species-specific. For this reason, today, there is no clear anesthetic of choice [30,31]. On the other hand, no anesthetic drug has been shown to be clearly teratogen in humans [8].

\section{Conclusion}

The issue of operating on pregnant women for spinal pathologies is rarely encountered in neurosurgical clinical practice. This may explain the lack of clear recommendations in terms of perioperative management. Nevertheless, spinal surgery on pregnant women seems to be safe for the mother and the fetus if a few modifications of the surgical and anesthetic techniques are applied. In our study, we did not encounter any perinatal mortality or any congenital malformations after surgical treatment during pregnancy. To summarize the current knowledge and evidence, the primary considerations should therefore be as follows [7] (Table 3):

- Perform native MRI without contrast enhancement for diagnostics

- Reduce fluoroscopic control during surgery if possible

- Maintain sufficient uteroplacental perfusion (prevent hypotension, mean arterial blood pressure at or above $70 \mathrm{mmHg}$ )
- Avoid aortocaval compression through adequate positioning (prone for first, lateral for second and third trimester)

- Select drugs with sufficient safety data (although no anesthetic has been identified as teratogen)

- If possible, use regional anesthesia (rare in spinal disorders)

- Use CTG/ultrasound device monitoring for perioperative monitoring (after 24 weeks of gestation).

Author contributions VB, HH, JR, SL, NK and MW made substantial contributions to conception and design, acquisition of data, analysis and interpretation of data; VB and MW have been involved in drafting the manuscript or revising it critically for important intellectual content; MW, SL, MB, CT, PV, ET, SE, JK and BM given final approval of the version to be published. VB and MW agreed to be accountable for all aspects of the work in ensuring that questions related to the accuracy or integrity of any part of the work are appropriately investigated and resolved.

Funding Open Access funding enabled and organized by Projekt DEAL. The study was funded by the Technical University of Munich.

Availability of data and materials The datasets used and/or analyzed during the current study available from the corresponding author on reasonable request.

\section{Compliance with ethical standards}

Competing interests All authors report no conflict of interest concerning the materials or methods used in this study or the findings specified in this publication.

Ethical Approval The research conducted has been performed in accordance with the Declaration of Helsinki. Approval for the study was obtained from the ethics committees of the Technical University of Munich (Votum Number 83/17 S) and University of Innsbruck (Votum Number 1239/2017).

Informed Consent Informed consent for publication was obtained.

Open Access This article is licensed under a Creative Commons Attribution 4.0 International License, which permits use, sharing, adaptation, distribution and reproduction in any medium or format, as long as you give appropriate credit to the original author(s) and the source, provide a link to the Creative Commons licence, and indicate if changes were made. The images or other third party material in this article are included in the article's Creative Commons licence, unless indicated otherwise in a credit line to the material. If material is not included in 
the article's Creative Commons licence and your intended use is not permitted by statutory regulation or exceeds the permitted use, you will need to obtain permission directly from the copyright holder. To view a copy of this licence, visit http://creativecommons.org/licenses/by/4.0/.

\section{References}

1. Fast A, Shapiro D, Ducommun EJ, Friedmann LW, Bouklas T, Floman Y (1987) Low-back pain in pregnancy. Spine (Phila Pa) 12(4):368-371. https://doi.org/10.1097/00007632-19870 5000-00011

2. Kristiansson P, Svärdsudd K, von Schoultz B (1996) Serum relaxin, symphyseal pain and back pain during pregnancy. Am J Obstet Gynecol 175(5):1342-1347. https://doi.org/10.1016/s0002 -9378(96)70052-2

3. LaBan MM, Perrin JC, Latimer FR (1983) Pregnancy and the herniated lumbar disc. Arch Phys Med Rehabil 64(7):319-321

4. Brown MD, Levi AD (1976) Surgery for lumbar disc herniation during pregnancy. Spine Phila Pa 26(4):440-443. https://doi. org/10.1097/00007632-200102150-00022

5. Han IH, Kuh SU, Kim JH, Chin DK, Kim KS, Yoon YS, Jin BH, Cho YE (2008) Clinical approach and surgical strategy for spinal diseases in pregnant women: a report of ten cases. Spine (Phila Pa 1976) 33 (17):E614-619. doi:https://doi.org/10.1097/BRS.0b013 e31817c6c7d

6. Voigt MFC, Olbertz D et al (2006) Analyse des Neugeborenenkollektivs der Bundesrepublik Deutschland 12. Mitteilung: Vorstellung engmaschiger Perzentilwerte (-kurven) für die Körpermaße Neugeborener. Geburtshilfe Frauenheilkd 66:956-970

7. Kuczkowski KM (2006) Nonobstetric surgery in the parturient: anesthetic considerations. J Clin Anesth 18(1):5-7. https://doi. org/10.1016/j.jclinane.2005.11.003

8. Practice ACoO (2011) ACOG Committee Opinion No 474: nonobstetric surgery during pregnancy. Obstet Gynecol 117 (2 Pt 1):420-421. https://doi.org/10.1097/AOG.0b013e31820eede9

9. Kort B, Katz VL, Watson WJ (1993) The effect of nonobstetric operation during pregnancy. Surg Gynecol Obstet 177(4):371-376

10. Mazze RI, Källén B (1989) Reproductive outcome after anesthesia and operation during pregnancy: a registry study of 5405 cases. Am J Obstet Gynecol 161(5):1178-1185. https://doi. org/10.1016/0002-9378(89)90659-5

11. Litmanovich D, Bankier A (2012) Radiation Dose from multidetector CT. CT scanning in pregnancy. Springer, Berlin

12. Patel SJ, Reede DL, Katz DS, Subramaniam R, Amorosa JK (2007) Imaging the pregnant patient for nonobstetric conditions: algorithms and radiation dose considerations. Radiographics 27(6):1705-1722. https://doi.org/10.1148/rg.276075002

13. Shellock FG, Crues JV (2004) MR procedures: biologic effects, safety and patient care. Radiology 232(3):635-652. https://doi. org/10.1148/radiol.2323030830

14. Chartier AL, Bouvier MJ, McPherson DR, Stepenosky JE, Taysom DA, Marks RM (2019) The Safety of maternal and fetal MRI at 3 T. AJR Am J Roentgenol 213(5):1170-1173. https:// doi.org/10.2214/AJR.19.21400

15. Kanal E, Barkovich AJ, Bell C, Borgstede JP, Bradley WG, Froelich JW, Gilk T, Gimbel JR, Gosbee J, Kuhni-Kaminski E, Lester JW, Nyenhuis J, Parag Y, Schaefer DJ, Sebek-Scoumis EA, Weinreb J, Zaremba LA, Wilcox P, Lucey L, Sass N, Safety ABRPoM, (2007) ACR guidance document for safe MR practices: 2007. AJR Am J Roentgenol 188(6):1447-1474. https://doi.org/10.2214/ AJR.06.1616

16. De Wilde JP, Rivers AW, Price DL (2005) A review of the current use of magnetic resonance imaging in pregnancy and safety implications for the fetus. Prog Biophys Mol Biol 87(2-3):335353. https://doi.org/10.1016/j.pbiomolbio.2004.08.010

17. Kanal E, Barkovich AJ, Bell C, Borgstede JP, Bradley WG, Froelich JW, Gimbel JR, Gosbee JW, Kuhni-Kaminski E, Larson PA, Lester JW, Nyenhuis J, Schaefer DJ, Sebek EA, Weinreb J, Wilkoff BL, Woods TO, Lucey L, Hernandez D (2013) ACR guidance document on MR safe practices: 2013. J Magn Reson Imaging 37(3):501-530. https://doi.org/10.1002/jmri.24011

18. Ray JG, Vermeulen MJ, Bharatha A, Montanera WJ, Park AL (2016) Association between MRI exposure during pregnancy and fetal and childhood outcomes. JAMA 316(9):952-961. https://doi. org/10.1001/jama.2016.12126

19. Nelson EM, Monazzam SM, Kim KD, Seibert JA, Klineberg EO (2014) Intraoperative fluoroscopy, portable x-ray and CT: patient and operating room personnel radiation exposure in spinal surgery. Spine J 14(12):2985-2991. https://doi.org/10.1016/j.spine e.2014.06.003

20. Kathirgamanathan A, Jardine AD, Levy DM, Grevitt MP (2006) Lumbar disc surgery in the third trimester-with the fetus in utero. Int J Obstet Anesth 15(2):181-182. https://doi.org/10.1016/j. ijoa.2005.10.007

21. Vougioukas VI, Kyroussis G, Gläsker S, Tatagiba M, Scheufler KM (2004) Neurosurgical interventions during pregnancy and the puerperium: clinical considerations and management. Acta Neurochir Wien 146(12):1287-1291. https://doi.org/10.1007/s0070 1-004-0354-9

22. Dashe JS, Gilstrap LC (1997) Antibiotic use in pregnancy. Obstet Gynecol Clin North Am 24(3):617-629. https://doi.org/10.1016/ s0889-8545(05)70326-0

23. Brandlistuen RE, Ystrom E, Nulman I, Koren G, Nordeng H (2013) Prenatal paracetamol exposure and child neurodevelopment: a sibling-controlled cohort study. Int J Epidemiol 42(6):1702-1713. https://doi.org/10.1093/ije/dyt183

24. Källén B, Reis M (2015) Use of tramadol in early pregnancy and congenital malformation risk. Reprod Toxicol 58:246-251. https ://doi.org/10.1016/j.reprotox.2015.10.007

25. Kristensen DM, Hass U, Lesné L, Lottrup G, Jacobsen PR, Desdoits-Lethimonier C, Boberg J, Petersen JH, Toppari J, Jensen TK, Brunak S, Skakkebaek NE, Nellemann C, Main KM, Jégou B, Leffers H (2011) Intrauterine exposure to mild analgesics is a risk factor for development of male reproductive disorders in human and rat. Hum Reprod 26(1):235-244. https://doi.org/10.1093/ humrep/deq323

26. Liu X, Liew Z, Olsen J, Pedersen LH, Bech BH, Agerbo E, Yuan W, Li J (2016) Association of prenatal exposure to acetaminophen and coffee with childhood asthma. Pharmacoepidemiol Drug Saf 25(2):188-195. https://doi.org/10.1002/pds.3940

27. Ofori B, Oraichi D, Blais L, Rey E, Bérard A (2006) Risk of congenital anomalies in pregnant users of non-steroidal anti-inflammatory drugs: A nested case-control study. Birth Defects Res B Dev Reprod Toxicol 77(4):268-279. https://doi.org/10.1002/bdrb.20085

28. Ní Mhuireachtaigh R, O'Gorman DA (2006) Anesthesia in pregnant patients for nonobstetric surgery. J Clin Anesth 18(1):60-66. https://doi.org/10.1016/j.jclinane.2004.11.009

29. Kunitz O, Rossaint R (2005) Anästhesie in der Schwangerschaft. Der Chirurg 76:737-743. https://doi.org/10.1007/s0010 4-005-1074-2

30. Kuczkowski KM (2004) Nonobstetric surgery during pregnancy: what are the risks of anesthesia? Obstet Gynecol Surv 59(1):5256. https://doi.org/10.1097/01.OGX.0000103191.73078.5F

31. Littleford $\mathbf{J}$ (2004) Effects on the fetus and newborn of maternal analgesia and anesthesia: a review. Can J Anaesth 51(6):586-609. https://doi.org/10.1007/BF03018403

Publisher's Note Springer Nature remains neutral with regard to jurisdictional claims in published maps and institutional affiliations. 


\section{Authors and Affiliations}

Vicki M. Butenschoen ${ }^{1}(1) \cdot$ Hanna Hitscherich ${ }^{1}$ - Sven O. Eicker ${ }^{2}$. Silvia M. Lobmaier ${ }^{6}$. Judith Rösler ${ }^{3}$. Martin Bretschneider ${ }^{7}$. Jan S. Kirschke ${ }^{8} \cdot$ Peter Vajkoczy $^{3} \cdot$ Nikolaus Kögl $^{4} \cdot$ Paul Constanthin $^{5} \cdot$ Claudius Thome $^{4}$. Enrico Tessitore $^{5} \cdot$ Bernhard Meyer $^{1} \cdot$ Maria Wostrack $^{1}$

\author{
Hanna Hitscherich \\ Hanna.Hitscherich@gmx.de \\ Sven O. Eicker \\ Eicker.s@mac.com \\ Silvia M. Lobmaier \\ silvia.lobmaier@tum.de \\ Judith Rösler \\ judith.roesler@charite.de \\ Martin Bretschneider \\ martin.bretschneider@tum.de \\ Jan S. Kirschke \\ jan.kirschke@tum.de \\ Peter Vajkoczy \\ Peter.Vajkoczy@charite.de \\ Nikolaus Kögl \\ Nikolaus.Koegl@tirol-kliniken.at \\ Paul Constanthin \\ Paul.Constanthin@hcuge.ch \\ Claudius Thome \\ Claudius.Thome@tirol-kliniken.at \\ Enrico Tessitore \\ Enrico.Tessitore@hcuge.ch \\ Bernhard Meyer \\ Bernhard.Meyer@tum.de
}

Maria Wostrack

Maria.Wostrack@tum.de

1 Department of Neurosurgery, Klinikum Rechts Der Isar, Technical University, Ismaningerstr. 22, 81675 Munich, Germany

2 Department of Neurosurgery, UKE Hamburg-Eppendorf, Martinistr. 52, 20251 Hamburg-Eppendorf, Germany

3 Department of Neurosurgery, Universitätsklinikum Charité, Charitéplatz 1, 10117 Berlin, Deutschland

4 Department of Neurosurgery, Medical University of Innsbruck, Anichstr. 35, 6020 Innsbruck, Austria

5 Department of Neurosurgery, Hopitaux Universitaires de Genève, Rue Gabrielle-Perret-Gentil 4, 1205 Geneva, Switzerland

6 Department of Obstetrics and Gynecology, Klinikum Rechts Der Isar, Technische Universität München, Ismaningerstr. 22, 81675 Munich, Germany

7 Department of Anesthesiology, Klinikum Rechts Der Isar, Technische Universität München, Ismaningerstr. 22, 81675 Munich, Germany

8 Department of Neuroradiology, Klinikum Rechts Der Isar, Technische Universität München, Ismaningerstr. 22, 81675 Munich, Germany 